in the stools may have come from the stomach); recurring attacks of jaundice; the pigmentation of the skin. Having present so many of the prominent symptoms of a typical case of splenic anemia are we justified in making a diagnosis of splenic anemia? Cases 14 and 18 in Osler's series correspond very closely to ours in every detail, having an enlarged spleen, secondary anemia, pigmentation of the skin, hematuria, jaundice, and in addition, cirrhosis of the liver, which, however, was not demonstrable until late in the disease.

In the case under consideration there was no liver cirrhosis nor any history of ascites. These conditions are, however, usually found only in the advanced stages of splenic anemia. The splenic enlargement is not as large as that reported in most cases of long-standing anemia. Its size might, indeed, be due to chronic congestion and hypertrophy of the tissues secondary to torsion of the pedicle.

In the present case there was a peculiar nodular condition of the skin which came on about one year after the tumor was first discovered. Does this bear any relation to the disease? In reviewing the literature at my command I find no mention of such a condition in splenic anemia. Oertel describes a somewhat similar appearance in a case of leukemia, but there was no such pigmentation associated with it. Kreibich describes another case of leukemic lesions of the skin, associated with some pigmentation, but the patient had been taking arsenic for some time previously, and this might have caused the pigmentation. Pinkus also describes a case of lymphatic leukemic lesions of the skin. Since all of these cases are positively of a leukemic nature, our case is, so far as I can ascertain, the only one of splenic anemia associated with a nodulation of the skin.

Our case was exhibited before the Chicago Dermatological Society, and the opinion was generally expressed that the nodulation was of the nature of a molluscum fibrosum.

\section{A FEW PRACTICAL POINTS IN THE TECHNIC OF NEPHRORRHAPHY AND HERNIOTOMY,}

AND A NEW MODIFICATION OF ALEXANDER'S OPERA'TION. F. P. CANAC-MARQUIS, M.D.

CHIEF SGRGEON OF THE FRENCH HOSPITAL. SAN FRANCISCO.

In presenting this paper to the medical profession, I wish merely to call attention to a few simple details that I have found of such practical benefit that my results are far superior to what they formerly were.

By referring to my case-books I note that the cases operated on prior to 1890 and in which I followed the technic then in vogue, are not to be compared in practical results, rapidity of healing and permanent benefits, to my subsequent cases, in which I followed the technic here given.

\section{NEPHRORRHAPFIY.}

An incision $10 \mathrm{~cm}$. long is made $4 \mathrm{~cm}$. from the spine and $2 \mathrm{~cm}$. below the twelfth rib and parallel to it, cutting through the skin, fascia and muscles. The finger is inserted in the incision and the peritoneum is pushed out of harm's way. The fatty capsule of the kidney is caught, opened and resected in the dorsal part of the kidney. The capsule proper is now incised to the extent of $8 \mathrm{~cm}$. on its dorsum, the capsule then freed 3 or $4 \mathrm{~cm}$. in all directions by the finger.

The slight bleeding that follows this denudation is easily arrested by compression. To anchor the kidney, a double silkworm-gut continuous suture is made on each side of the incision, starting at A (Fig. 1), passing through the skin, fat, muscle and capsule proper; taking about $1 \mathrm{~cm}$. of the muscles with the capsule proper and passing out in the inverse order, as shown in Figure 1 at $A$. The same procedure for the opposite side is shown at $B$ and $B^{\prime}$. By pulling these sutures taut, the capsule is drawn to the side and exposes a raw surface of kidney parenchyma about $3 \mathrm{~cm}$. wide and $6 \mathrm{~cm}$. long. A lead nickel-plated shield is threaded and shotted and the shot crushed on these sutures, when moderate tension has been accomplished.

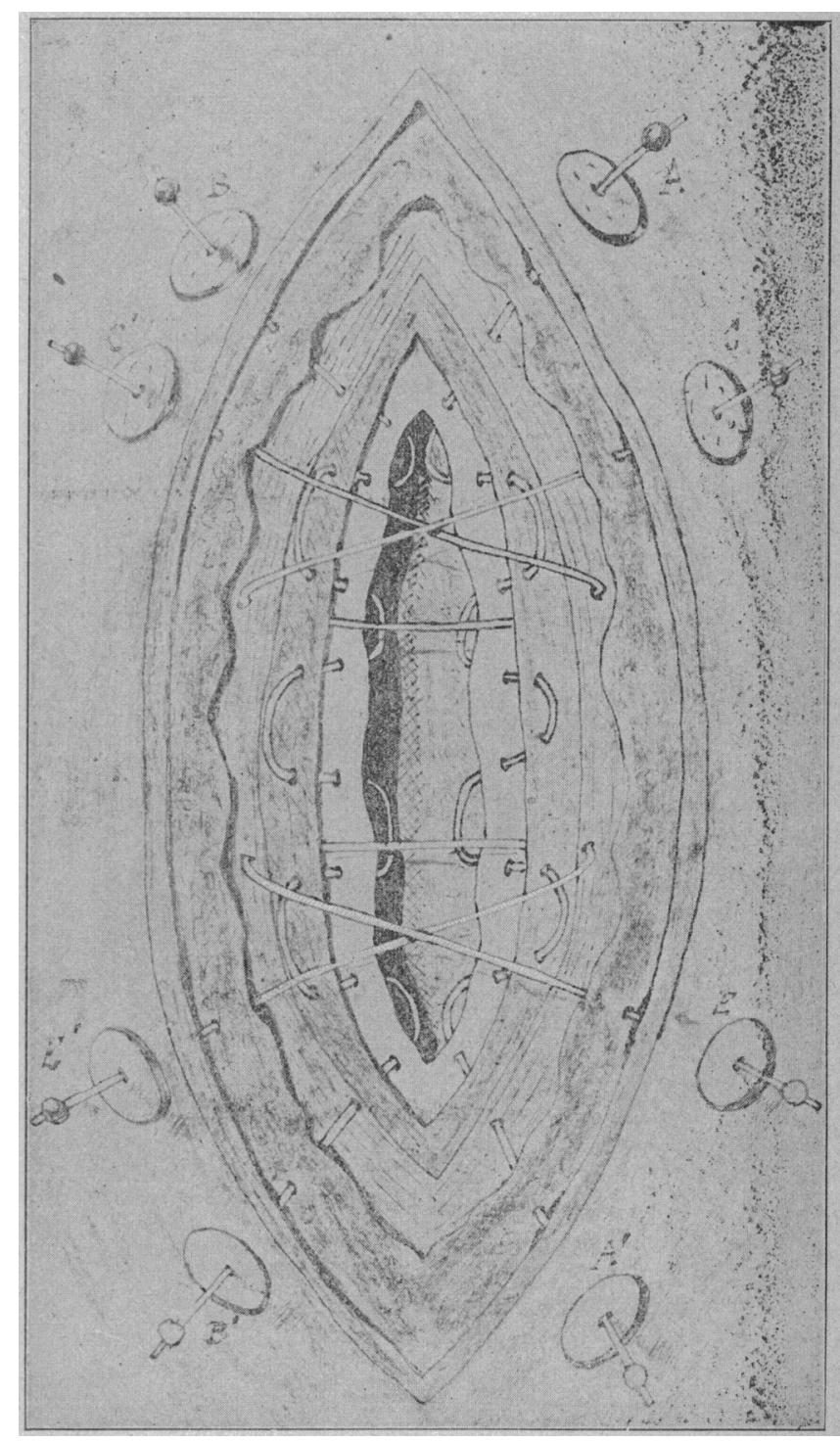

Figure 1.

The next step in this operation is to draw the muscles over the raw surface of the kidney, which is accomplished by passing double silkworm-gut sutures, starting at C, going through skin and fat, crossing over and taking in all of the muscles of opposite side, then recrossing over surface of kidney to take the muscles of the side whence suture started; to be recrossed and take in fat and skin, as shown in Figure 1, $\mathrm{C}^{\prime}$. The same procedure is followed in lower angle of incision, as shown in Figure $1, \mathrm{E}$ and $\mathrm{E}^{\prime}$. If necessary, one or two more of this sort of figure-of-eight suture may be made, as shown in Figure 2.

When these figure-of-eight-like sutures are made tense, they serve to draw the muscle edge together and bring 
their posterior raw surface in contact with the raw surface of the kidney parenchyma, at the same time bringing the adipose and skin in opposition. The "agraffes" (hooks) of Dr. Michel serve to make linear apposition of the skin, as shown in Figure 3.

The only dressing made is plain sterile gauze with tight-fitting abdominal bandage. 'The patient is kept

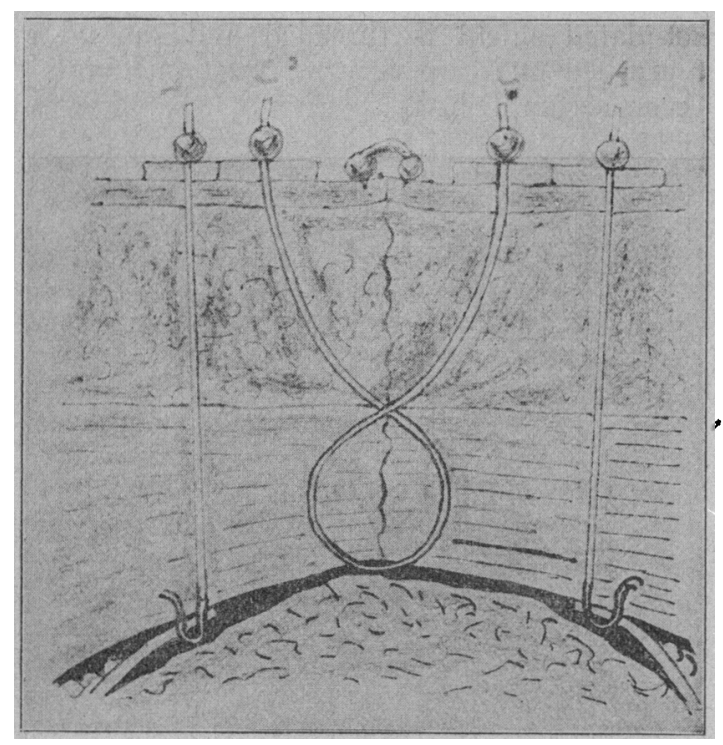

Figure 2.

in dorsal decubitus for about twenty days. The third day the agraffes of Michel are removed and collodion with absorbent cotton applied to skin incision.

On the twelfth to fifteenth day the shot and shield of $A$ and $B^{\prime}, C$ and $E^{\prime}$, are removed, leaving the sutures to loosen by the respiratory movements, so as to avoid

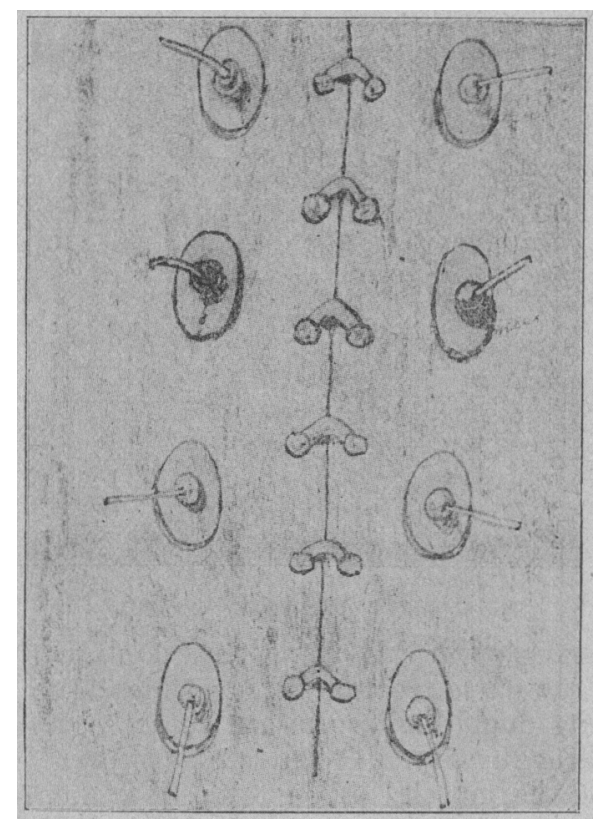

Figure 3.

pain and the possible breaking of the sutures in its final removal, a few days afterward.

By this method, it will be noticed, there are no buried sutures left to serve as a cause for future trouble.

Should there be an excess of oozing, a small strip of gauze may be left for drainage between sutures $C$ and $\mathrm{E}$ and removed the second or third day of operation.
Since 1890 I have performed this operation 281 times, following this technic, and have never yet observed a failure. At this time it may serve a useful purpose to remark that in ten cases of double nephrorrhaphy, where, prior to operation, there had existed chronic nephritis and enlarged kidneys, with albumin and granular casts in the urine, in a few months following operation the urine cleared itself of pathologic products, and an evident diminution in the size of the kidneys was apparent, which I attributed to the freeing of the capsule of the kidney and the improved circulation in that organ.

In sixteen cases of single nephrorrhaphy, where the floating kidney was enlarged and congested, the bene-

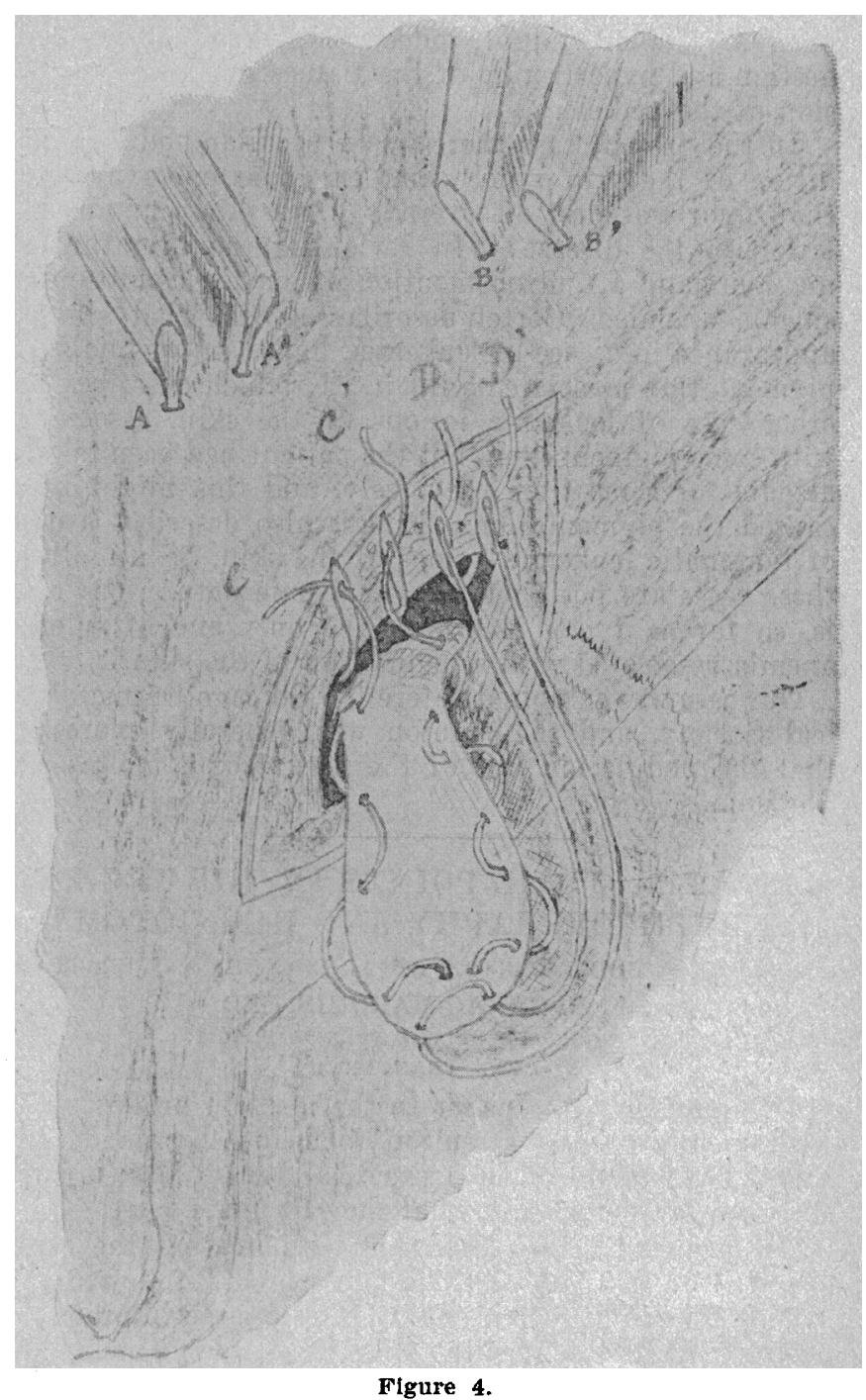

ficial effects of the operation were apparent in thirty days and the kidney practically restored to normal in two months following the operation.

TECHNIC OF HERNIOTOMY FOR RADICAL CURE OF HERNIA.

An oblique incision of the skin $5 \mathrm{~cm}$. long is made parallel to the pillars of the inguinal canal. With the finger separate all the cellular tissue until the vas deferens is reached. Gentle traction is now made on the vas deferens, which brings the sac into view, which is usually attached thereto. The sac is now freed from the cord and adjacent structures, and for a distance of $3 \mathrm{~cm}$. around and within the internal abdominal ring. 
A curved needle, armed with double silkworm-gut sutures, is inserted at the neck of the sac, following its edge in the entire length of the sac, keeping to the margin, across the fundus and up the opposite edge, making a purse-string suture, as shown in Figure 4,

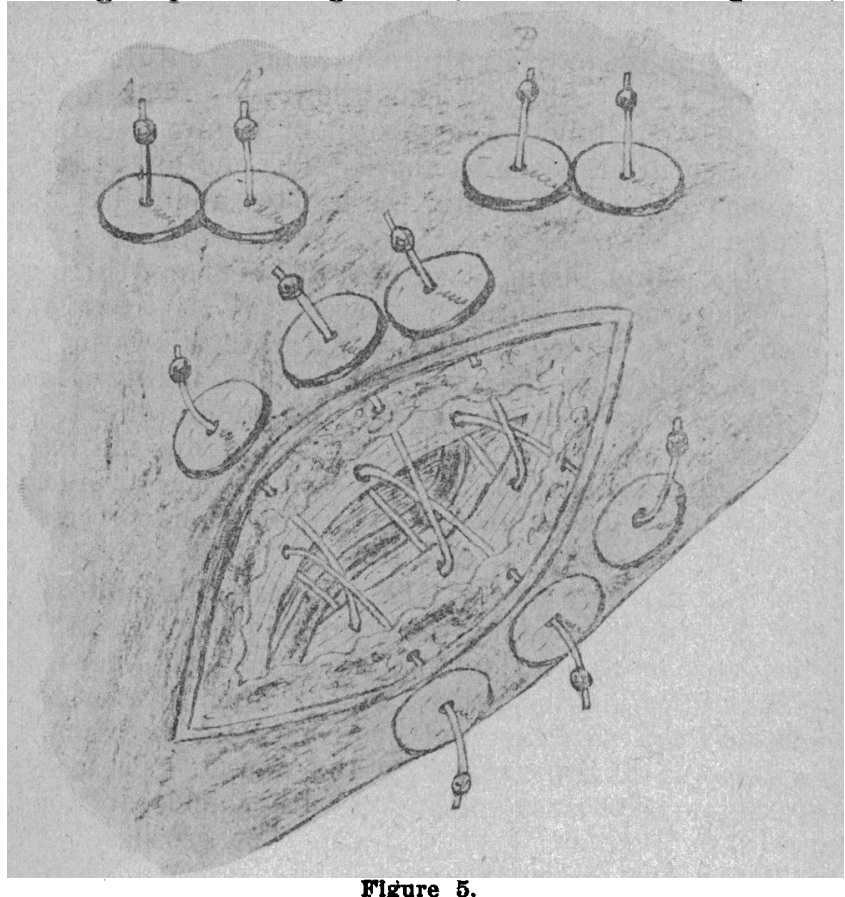

$\mathrm{C}$ and $\mathrm{C}^{\prime}$. A second double silkworm-gut suture is now passed through the fundus of the sac, as shown in Figure $4, \mathrm{D}$ and $\mathrm{D}^{\prime}$.

Now the finger is inserted through the external ring,

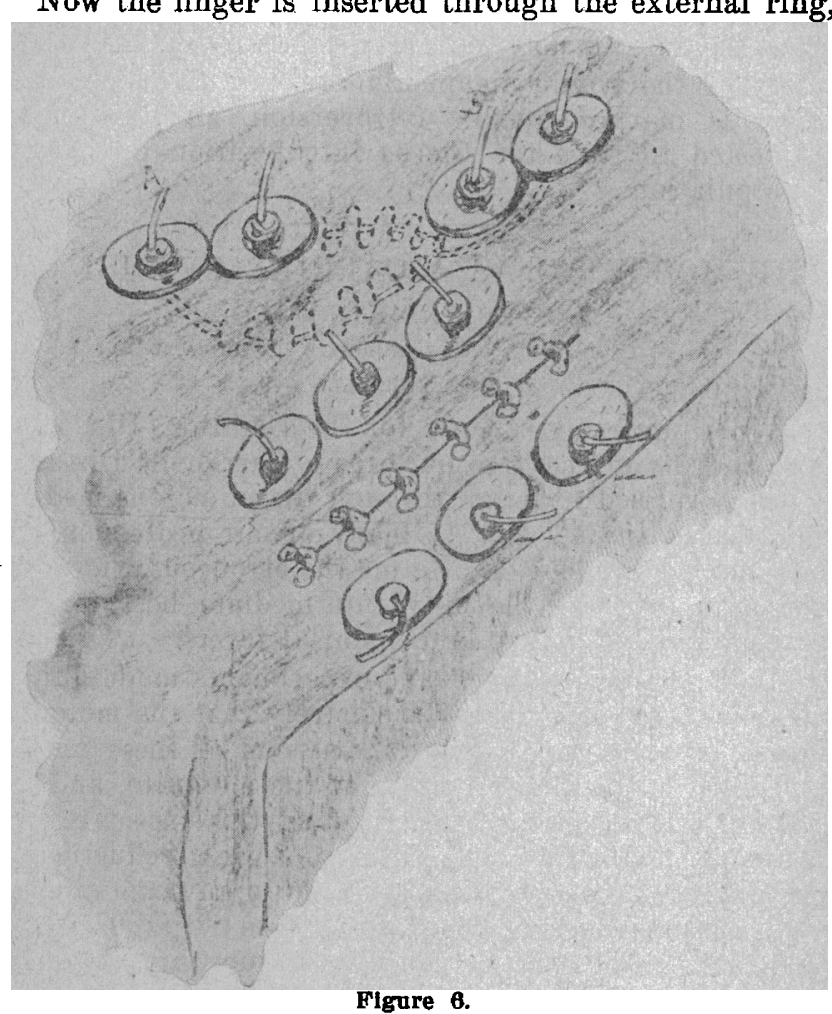

between the peritoneum and abdominal wall. A Doyen's needle is inserted $4 \mathrm{~cm}$. above the pillars and $3 \mathrm{~cm}$. internal, i. e., towards the median line, as shown in A, Figure 4, and passed through skin, fascia and muscles until the finger is reached, and on which it is guided through the wound. Suture $C$ is now threaded to this needle and brought out at $A$. This same process is followed in $A^{\prime}$ by inserting needle $11 / 2 \mathrm{~cm}$. external to $A$, and on which thread $\mathrm{C}^{\prime}$ is passed and brought out at $\mathrm{A}^{\prime}$.

These sutures are now held by forceps. About $3 \mathrm{~cm}$. external to $A^{\prime}$ and parallel to it, the Doyen's needle

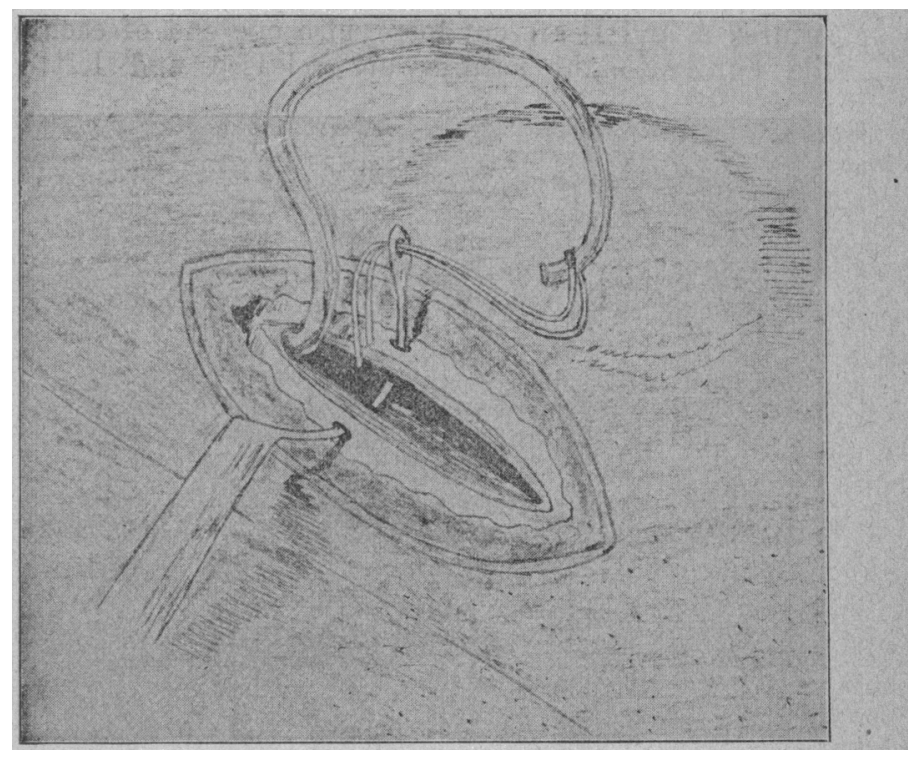

Figure 7 .

is inserted as previously described, and threaded with suture $D$, and drawn through $B ; 11 / 2 \mathrm{~cm}$. external to this suture the needle is again inserted as above and threaded with $\mathrm{D}^{\prime}$ and drawn out at $\mathrm{B}^{\prime}$. Suture $\mathrm{A}$ and $A^{\prime}$ are drawn moderately tense and threaded with shields and shot, and shot crushed.

The same process is followed with suture $\mathrm{B}$ and $\mathrm{B}^{\prime}$. It will be readily seen that drawing taut sutures $A$ and $\mathbf{A}^{\prime}$ and $B$ and $B^{\prime}$, the hernial sac is held taut between the

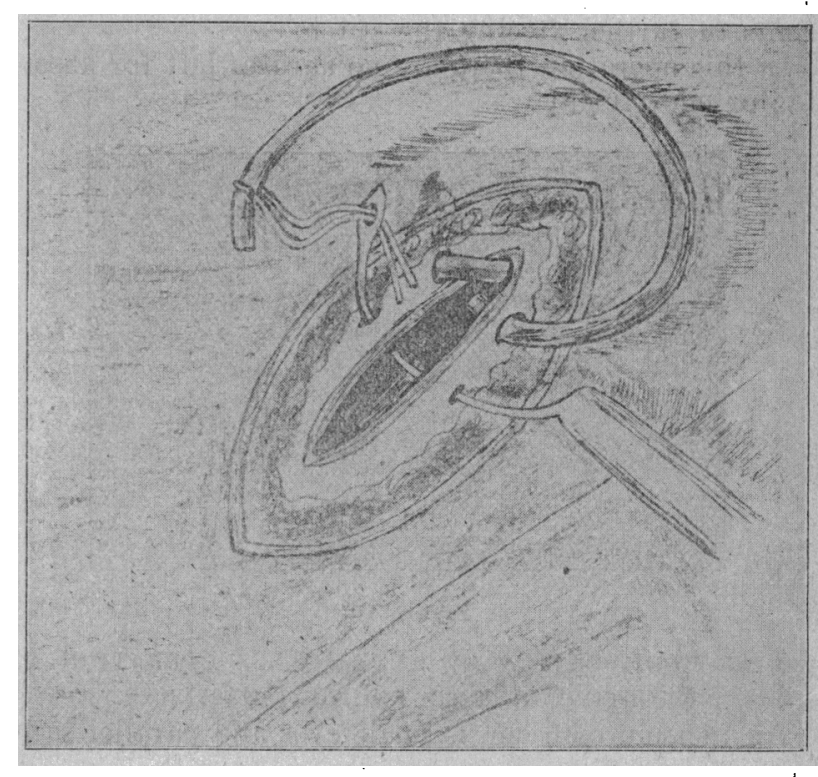

Figure 8.

parietal peritoneum and abdominal wall, making a bulwark above the internal ring, which serves at all times to resist any intra-abdominal pressure.

The cord is replaced in its normal bed and the pillars and abdominal wound carefully closed over it by two 
or three figure-of-eight sutures, as described in the technic of nephrorrhaphy and shown in Figure 5.

The final closing of the wound and schematic drawing of the folded sac is shown in Figure 6 .

On the third day the Michel hooks are removed and collodion and absorbent cotton applied to the skin incision.

On the tenth to the twelfth day the shot-holding sutures $\mathrm{A}$ and $\mathrm{B}$ are cut loose, also one end of each of the figure-of-eight sutures are released and left in

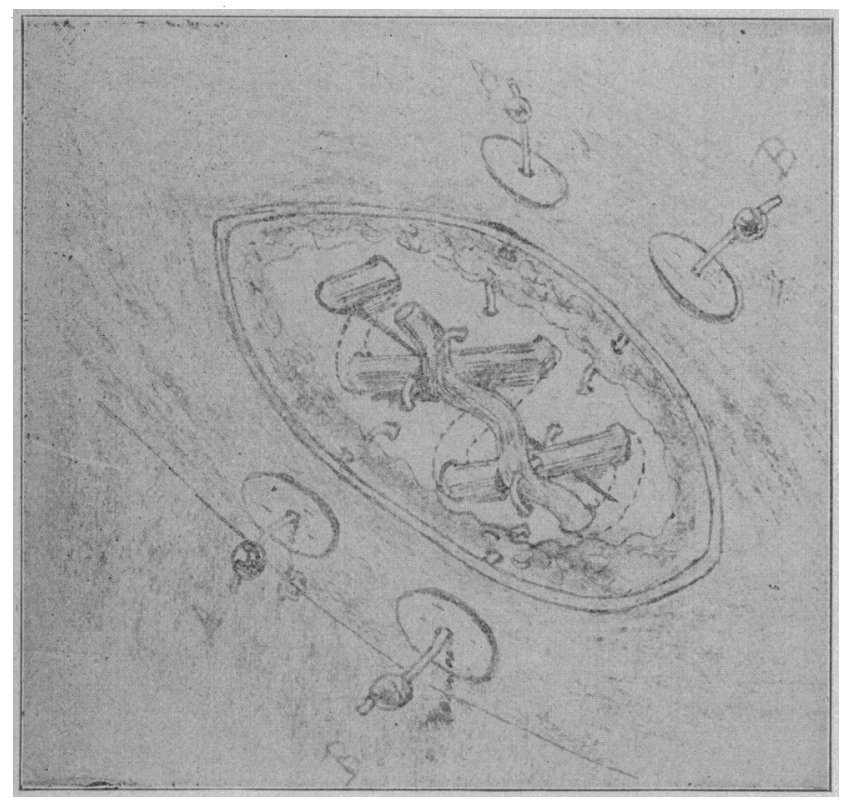

Firuie 9.

pasition for two or three days more, at which time they are easily removed without pain.

Should, at this time, it be found difficult to remove the folded stitch $A$ and $A^{\prime}$, a small strip of gauze is wound under the remaining shield so as to form a cushion which will serve to assist the respiratory movements in further freeing the stitch.

In this operation there are no sutures left for absorption or encystment.

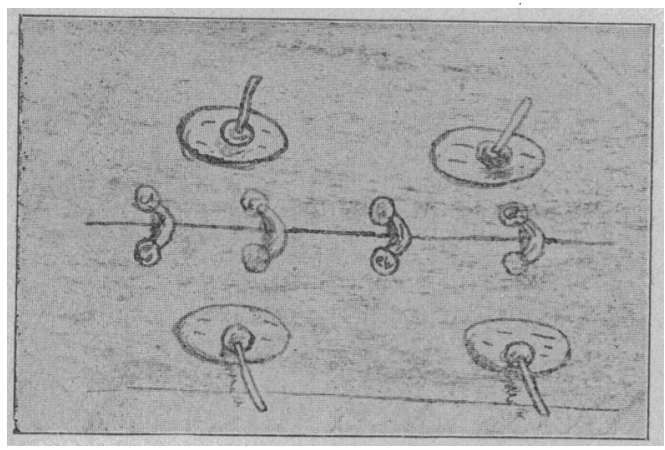

Figure 10.

A NEW MODIFICATION OF ALEXANDER'S OPERATION FOR SHORTENING THE ROUND LIGAMENTS.

An incision of $6 \mathrm{~cm}$. is made over and parallel to the inguinal canal through the skin; with the finger dissect the fatty tissue down to the fascia. With the assistance of a grooved director, ferforate the fascia over the inguinal ring. The small bunch of pearly white, fatty tissue, commonly found over the inguinal ring, is picked up, and on the inferior side is found the round ligament. This is now carefully dissected from its peritoneal hood for a space of 10 or $12 \mathrm{~cm}$. A silkworm-gut suture is tied at its distal end. A Deschamp's needle is passed through the fascia and muscle of the inguinal ring about $1 / 2 \mathrm{~cm}$. from its edge and threaded with the silkworm-gut suture, as shown in Figure $\%$.

The round ligament is made to follow this carrier suture and its own structure used as a suture of the inguinal ring. About $2 \mathrm{~cm}$. below, this same method of suturing is followed, as shown in Figure 8. Again, a third suture is made as above. The end of the round ligament is overlapped over the last two round ligament sutures.

These round ligament sutures are anchored in place by silkworm-gut sutures, placed in the following manner: A curved needle, armed with silkworm gut, is passed through the skin and fat and taking a loop of fascia, then passing through the middle of the two crossed round ligaments, dipping again into the fascia and coming through the fat and skin of opposite side, as shown in Figure 9, $A$ and $A^{\prime}$. This same process is followed for suture $B$ and $B^{\prime}$.

It will be noticed that the inguinal ring and canal will thus be sutured by the round ligament itself and reinforced by its overlapping, which in turn is anchored by a silkworm-gut suture, which, when drawn taut, presses them together and overcomes the necessity of leaving any buried sutures in the wound. These silkworm-gut sutures are threaded with shields and shot, drawn moderately tense and the shot crushed. The Michel hooks are used for the close approximation of the skin edges, and removed the second or third day, and the line of incision covered with collodion and absorbent cotton. In about fifteen days following the operation, shot $A$ and $B^{\prime}$ are cut off and the suture left for three or four days more to partly free itself, at which time the sutures may be removed painlessly.

When the round ligaments are illy developed and there is marked uterine retroversion, an assistant is requested to raise the uterus into position by vaginal manipulation.

\section{THE MOSQUITO AS A CARRIER OF DISEASE.} J. STEBBINS KING, M.D. LATE U. S. ARMT SURGEON IN CUBA. DECATUR, ILL.

While preparing a paper for the Decatur (Ill.) Medical Society on the "Mosquito as a Carrier of Disease," I was surprised to learn, through the numerous medical journals consulted, that so many of our profession had adopted the extreme, and to me the erroneous, view that the mosquito was the only intermediate host for the transmission of yellow and malarial fevers.

While the various scientific experiments made during the past few years prove conclusively that the mosquito is one great factor in the transmission of these fevers; and that by the extermination of the mosquito, and the proper precautions against allowing this insect to bite those afflicted with these diseases, a great reduction of the number of patients can be made in any community; yet, in my estimation, the evidence does not establish the fact that the mosquito is the only medium through which these fevers can be propagated. Those who maintain that it is claim that the experiments in Cuba, in 1900, of the board for the "Study of the Etiology and Prevention of Yellow Fever," prove the correctness of this, as to yellow fever. It may prove so to those who have not had any practical experience in the treatment and 